\title{
Performances on the Timed Up and Go Test and subtasks between fallers and non-fallers in older adults with cognitive impairment
}

\author{
Performances no teste Timed Up and Go e subtarefas em idosos com comprometimento \\ cognitivo, caidores e não caidores
} Juliana Hotta Ansai', Larissa Pires de Andrade², Theresa Helissa Nakagawa², José Rubens Rebelatto²

\begin{abstract}
This work aimed to compare performances on the Timed Up and Go (TUG) test and its subtasks between faller and non-faller older adults with mild cognitive impairment (MCl) and mild Alzheimer's disease (AD). A prospective study was conducted, with 38 older adults with $\mathrm{MCl}$ and 37 with mild AD. Participants underwent an assessment at baseline (the TUG and its subtasks using the Qualisys ProReflex system) and the monitoring of falls at the six-month follow up. After six months, $52.6 \%$ participants with $\mathrm{MCl}$ and $51.3 \%$ with $\mathrm{AD}$ fell. In accordance with specific subtasks, total performance on the TUG distinguished fallers from non-fallers with AD, fallers from non-fallers with $\mathrm{MCl}$ and non-fallers with $\mathrm{MCl}$ from non-fallers with $\mathrm{AD}$. Although no other difference was found in total performances, non-fallers with $\mathrm{MCl}$ and fallers with $A D$ differed on the walking forward, turn and turn-to-sit subtasks; and fallers with $\mathrm{MCl}$ and non-fallers with $\mathrm{AD}$ differed on the turn-to-sit subtask.
\end{abstract}

Keywords: aged; Alzheimer's disease; accidental falls; cognitive disfunction.

RESUMO

O objetivo deste trabalho foi comparar o desempenho do Timed up and go test (TUG) e suas subtarefas entre idosos caidores e não caidores com comprometimento cognitivo leve (CCL) e doença de Alzheimer (DA) leve. Um estudo prospectivo foi conduzido, com 38 idosos com CCL e 37 com DA leve. Foi realizada uma avaliação inicial (TUG e subtarefas por meio do sistema Qualisys Pro Reflex) e um monitoramento de quedas por 6 meses. Após 6 meses, 52.6\% pessoas com CCL e 51.3\% com DA caíram. Em concordância com subtarefas específicas, a performance total do TUG distinguiu caidores de não caidores com DA, caidores de não caidores com CCL e não caidores com CCL de não caidores com DA. Embora nenhuma outra diferença foi encontrada na performance total do TUG, não caidores com CCL e caidores com DA apresentaram diferenças nas performances das subtarefas marcha ida, retornar e virar-se para sentar; e caidores com CCL e não caidores com DA diferiram na subtarefa virar-se para sentar.

Palavras-chave: idoso; doença de Alzheimer; acidentes por quedas; disfunção cognitiva.

Mobility impairment is common in older adults and one of the major causes of morbidity and mortality ${ }^{1}$. Among several mobility tests, the Timed Up and Go (TUG) test is simple, quick and widely used in clinical practice. Also, performance on the TUG can give added information about cognitive impairment and risk of falls ${ }^{2,3}$.

Previous studies have found differences in performance on the TUG between older people with mild cognitive impairment (MCI) and those with Alzheimer's disease (AD).
However, this difference remains unclear when evaluating people with $\mathrm{AD}$ in the mild phase $\mathrm{e}^{4,5}$. Regarding the risk of falls, the TUG is an accurate measure for screening risk of falls in community-dwelling older people ${ }^{2}$. Taylor et al. ${ }^{6}$ found a relationship between worse performance on the TUG and risk of falls in cognitively impaired older people.

Prevention and understanding about falls in older people with cognitive impairment are important, since there is a high

1 Universidade Federal do Mato Grosso do Sul; Departamento de Fisioterapia, Instituto Integrado de Saúde, Campo Grande MS, Brasil;

Universidade Federal de São Carlos, Departamento de Fisioterapia, São Carlos SP, Brasil;

${ }^{3}$ Centro Universitário do Norte, Departamento de Fisioterapia, Manaus AM, Brasil.

Correspondence: Juliana Hotta Ansai; Departamento de Fisioterapia da UFMS, Instituto Integrado de Saúde; Cidade Universitária, 79070-900; Campo Grande MS, Brasil; E-mail: juliana.h.ansai@ufms.br

Conflict of interest: There is no conflict of interest to declare.

Received 23 November 2017; Received in final form 28 February 2018; Accepted 05 March 2018.

Support: This study was supported by the Coordination for the Improvement of Higher Education Personnel (CAPES). The sponsor had no involvement in the study design, in the collection, analysis and interpretation of data. 
prevalence of falls in up to $60 \%$, with serious consequences ${ }^{4,7}$. It is known that older people with a risk of falls and people with cognitive impairment present a worse performance on the TUG. Therefore, performance on the TUG, in people with $\mathrm{MCI}$ and mild $\mathrm{AD}$, may be affected by the occurrence of falls. A better knowledge about these associations may be helpful for developing effective strategies to prevent mobility impairment. Also, not only the analysis of total performance on the TUG, but also performances on the TUG subtasks could facilitate the understanding of the risk of falls in older people with $\mathrm{MCI}$ and mild $\mathrm{AD}^{3,8}$.

The purpose of this study was to compare performances on the TUG and its subtasks between faller and non-faller older adults with MCI and mild AD. We hypothesized that the effects of $\mathrm{MCI} / \mathrm{mild} \mathrm{AD}$ on mobility are different in fallers and non-fallers.

\section{METHODS}

\section{Participants}

This was a six-month prospective study at the Federal University of São Carlos (São Paulo, Brazil) from 2014 to 2016. Community-dwelling older adults aged 65 years and older, who lived in São Carlos (Brazil), were recruited from health units and open universities for older adults. Inclusion criteria were the ability to walk at least 10 meters without a walking aid and a diagnosis of early-stage $\mathrm{AD}$ or MCI. Individuals with motor alterations after stroke, neurological disorders that interfered in cognition or mobility, advanced or moderate-stage $\mathrm{AD}$ and severe uncorrected visual or auditory disorders were excluded.

A neurologist confirmed the diagnosis of MCI and mild $\mathrm{AD}$. For the diagnosis of MCI, we considered the following criteria: (1) cognitive complaint, reported by the participant or an informant (a person who stayed with the participant at least half a day, four days per week); (2) objective cognitive impairment not related to delirium, with a score of 0.5 on the Clinical Dementia Rating Scale9; (3) normal global cognitive function for the educational level, as assessed by the Mini-Mental State Examination; (4) preserved function, as assessed by the Pfeffer Scale; and (5) absence of clinical dementia ${ }^{4}$. The diagnosis of $\mathrm{AD}$ was based on the Diagnosis and Statistical Manual of Mental Disorders ( fourth Edition $)^{10}$. The following criteria was used for mild AD: (1) objective cognitive impairment not related to delirium, manifested by memory deficit and at least one other cognitive function (language, praxis, gnosis and executive function), as assessed by the Addenbrooke Cognitive Examination; (2) cognitive decline severe enough to interfere with functionality, as assessed by the Pfeffer Scale; and (3) a score of 1.0 on the Clinical Dementia Rating Scale ${ }^{4,9}$.

Ethical approval was obtained from the Federal University of São Carlos ethics research committee. All participants provided written informed consent. The volunteers with mild
$\mathrm{AD}$ signed the informed consent, in the presence of an informant (a person who stayed with the participant at least half a day, four days per week).

\section{Measures}

Participants underwent an assessment at baseline, including anamnesis and performance on the TUG, and a monitoring of falls at the six-month follow up. With help of an informant (a person who stayed with the participant at least half a day, four days per week), age, gender, body mass index, years of schooling, number of diseases and medication and weekly caloric expenditure (Minnesota Leisure Time Activities Questionnaire score $)^{11}$ were collected.

\section{Performance on the TUG}

The volunteers performed the TUG in comfortable clothing, their usual closed shoes and, if necessary, visual or auditory aids. The Qualisys ProReflex motion analysis system with seven cameras (1280 x 1024 resolution; 1.3 megapixels) was used to assess the TUG and a single assessor (good intrarater reliability) placed the reflective markers on specific anatomic points. Markers of iliac spines, iliac crests, heel and metatarsal were used to screen the pelvis and foot. Clusters with reflective markers affixed in a non-collinear form were placed on thoracic and lumbar areas and on distal thirds of the thigh and leg to screen the trunk, thigh and $\operatorname{leg}^{12}$.

The volunteers performed the TUG test using the standardized length of the highway (three meters) ${ }^{2}$ and a chair $45 \mathrm{~cm}$ high with trunk support, $68 \mathrm{~cm}$-high armrests and with an adapted design for capturing markers by the camera. The instructions were standardized for all participants to maximize the consistency of the mobility assessment in those with varying comprehension difficulties ${ }^{12}$. The participants performed the TUG six times due to capture field limitations. The first three trials recorded sit-to-stand, walking forward and turn-to-sit subtasks and the last three trials recorded turn-to-walk and walking back subtasks. The average of these trials was analyzed and participants could rest between trials if required.

Data were processed by the Qualisys Track Manager software (Qualisys AB) (sampling frequency: $120 \mathrm{~Hz}$ ) and the Visual3D software (C-Motion, Inc, Germantown, MD). A MATLAB routine was applied to detect, separate and analyze the TUG subtasks (sit-to-stand, walking forward, turnto-walk, walking back and turn-to-sit) ${ }^{13,14}$. The detection of each subtask has been described previously ${ }^{12}$.

We analyzed the following measures: total time and number of steps spent on the TUG; time and average velocity of the trunk (flexion/extension movement) during the sit-tostand subtask; gait speed, number of steps, time and length of the first step during walking forward and walking back subtasks; time, number of steps and average velocity of the trunk (rotation movement) spent on the turn subtask; and time and average velocities of the trunk (flexion/extension and rotation movements) during the turn-to-sit subtask. 


\section{Falls}

Falls were monitored by a falls calendar and monthly telephone calls. The fall definition was "an event that results in a person coming to rest inadvertently on the ground or floor or other lower level, other than as a consequence of the following: sustaining a violent blow; loss of consciousness; sudden onset of paralysis; or an epileptic seizure" ${ }^{15}$. The person with the MCI participant confirmed all doubtful information, and the person with $\mathrm{AD}$ participant filled in the calendar and gave all the information.

After the follow-up period, the participant were divided into four groups: non-fallers with MCI, fallers with MCI, nonfallers with mild $\mathrm{AD}$ and fallers with mild $\mathrm{AD}$. We considered a faller as a person who fell at least once during the follow-up ${ }^{2,7}$.

\section{Statistical analysis}

Data were analyzed using SPSS statistics (20.0). The Kolmogorov-Smirnov test was used to determine whether data were normally distributed. Between-group analyses were examined using the Chi square test for categorical variables and the Kruskal-Wallis Test (post hoc: Mann-Whitney U test) for quantitative variables. Also, the ANCOVA test was applied to compare the TUG and its subtasks between faller and non-faller older adults (with cognitive condition as the confounding variable). The alpha level was set at 0.05 .

\section{RESULTS}

Initially, 40 volunteers with MCI and 38 volunteers with mild $\mathrm{AD}$ were assessed. Six older people with $\mathrm{AD}$ received physical therapy prior to the study and during the followup. Three participants $(\mathrm{MCI}=2, \mathrm{AD}=1)$ died before the follow-up, so their data were not analyzed. After six months, $20(52.6 \%)$ participants with MCI and 19 (51.3\%) participants with mild $\mathrm{AD}$ fell at least once. Among the fallers with MCI, five fell once, four fell twice, five fell three times and six fell four or more times. Among the fallers with $\mathrm{AD}$, six fell once, six fell twice, three fell three times and four fell four or more times. No significant difference in descriptive data and weekly caloric expenditure (Minnesota Leisure Time Activities Questionnaire score at baseline) was found between the four groups according to fall and cognitive status (Table 1).

Regarding the time/gait speed of the TUG and its subtasks, non-fallers with MCI spent significantly less time on the TUG compared with (i) non-fallers with $\mathrm{AD}$, which is consistent with performances on all subtasks except the sit-tostand subtask; and (ii) fallers with MCI, in accordance with performances on the walking forward, turn and walking back subtasks. Moreover, non-fallers with $\mathrm{AD}$ took more time to perform the TUG and turn-to-sit subtask compared to fallers with $\mathrm{AD}$ (Table 2).

Although no other difference was found in the TUG performance between groups, non-fallers with MCI had a lower time in the turn subtask and a higher gait speed in the walking forward subtask compared to fallers with AD. Still, fallers with $\mathrm{MCI}$ differed from non-fallers with $\mathrm{AD}$ when the time of the turn-to-sit subtask was analyzed (Table 2).

Regarding other mobility parameters of the TUG and subtasks, non-fallers with MCI showed a higher average velocity of the trunk (flexion/extension) in the sit-to-stand subtask than non-fallers with $\mathrm{AD}$. Also, non-fallers with MCI performed the turn subtask with a higher average velocity of the

Table 1. Descriptive data of participants.

\begin{tabular}{|c|c|c|c|c|c|}
\hline Variable, Md (IQR) & $\begin{array}{l}\text { Non-fallers with } \mathrm{MCl} \\
(\mathrm{n}=18)\end{array}$ & $\begin{array}{l}\text { Fallers with MC } \\
\qquad(n=20)\end{array}$ & $\begin{array}{c}\text { Non-fallers with mild } \\
\qquad D(n=18)\end{array}$ & $\begin{array}{l}\text { Fallers with mild AD } \\
\qquad(n=19)\end{array}$ & $p$-value \\
\hline Age (years) & $72.5(68.7-79.5)$ & $77.0(71.2-82.0)$ & $78.0(72.7-81.0)$ & $79.0(73.0-84.0)$ & 0.253 \\
\hline Female gender, n (\%) & $16(88.9)$ & $16(80.0)$ & $11(61.1)$ & $10(52.6)$ & 0.058 \\
\hline Body mass index $\left(\mathrm{kg} / \mathrm{m}^{2}\right)$ & $30.4(27.6-32.8)$ & $29.0(25.1-31.1)$ & $27.7(22.1-32.3)$ & $27.3(22.7-30.4)$ & 0.168 \\
\hline Years of schooling & $4.0(4.0-10.0)$ & $4.0(2.0-4.7)$ & $4.0(2.0-6.2)$ & $4.0(4.0-8.0)$ & 0.474 \\
\hline Diseases (number) & $2.0(2.0-3.2)$ & $3.0(2.0-4.0)$ & $3.0(2.0-4.0)$ & $4.0(3.0-5.0)$ & 0.070 \\
\hline Medication (number) & $4.0(2.7-6.5)$ & $5.0(3.0-7.0)$ & $5.0(2.7-6.0)$ & $5.0(4.0-6.0)$ & 0.659 \\
\hline Minnesota & $1,287.2(355.0-2,314.0)$ & $743.4(174.6-1724.3)$ & $353.8(95.6-1018.4)$ & $289.8(0.0-1161.1)$ & 0.138 \\
\hline
\end{tabular}

Md (IQR): median (interquartile range 25\%-75\%); $\mathrm{n} \%$ ): number of individuals (percentage); MCl: mild cognitive impairment; AD: Alzheimer's disease; kg/m²: kilograms per meter squared; Minnesota: Minnesota Leisure Time Activities Questionnaire score.

Table 2. Time/gait speed spent on the TUG and subtasks by group.

\begin{tabular}{|c|c|c|c|c|c|}
\hline Variable, Md (IQR) & $\begin{array}{l}\text { Non-fallers with } \mathrm{MCl} \\
(\mathrm{n}=18)\end{array}$ & $\begin{array}{l}\text { Fallers with } \mathrm{MCl} \\
\qquad(\mathrm{n}=20)\end{array}$ & $\begin{array}{l}\text { Non-fallers with mild AD } \\
\qquad(n=18)\end{array}$ & $\begin{array}{l}\text { Fallers with mild AD } \\
\qquad(n=19)\end{array}$ & $\mathrm{p}$-value \\
\hline TUG, total time (s) & $12.4(11.2-14.3)^{\#,+}$ & $14.4(11.8-17.2)^{\#}$ & $17.9(13.7-21.5)^{+, \$}$ & $14.0(12.4-17.8)^{\$}$ & 0.003 \\
\hline Sit-to-stand, time (s) & $0.8(0.7-1.0)$ & $0.9(0.8-1.0)$ & $0.9(0.8-1.2)$ & $0.9(0.7-1.0)$ & 0.390 \\
\hline Walking forward, gait speed (m/s) & $0.5(0.4-0.6)^{\#+,+\$}$ & $0.4(0.3-0.5)^{\#}$ & $0.4(0.2-0.5)^{+}$ & $0.4(0.3-0.5)^{\$}$ & 0.034 \\
\hline Turn, time (s) & $1.7(1.2-2.3)^{\#,+, \$}$ & $2.2(1.9-2.8)^{\#}$ & $2.5(2.1-2.8)^{+}$ & $2.6(2.1-2.8)^{\$}$ & 0.027 \\
\hline Walking back, gait speed (m/s) & $0.7(0.6-0.8)^{\#,+}$ & $0.6(0.4-0.7)^{\#}$ & $0.5(0.4-0.6)^{+}$ & $0.6(0.5-0.7)$ & 0.007 \\
\hline Turn-to-sit, time (s) & $1.8(1.6-2.3)^{+}$ & $2.0(1.8-2.7)^{\#}$ & $3.0(2.1-3.9)^{+, \$, \#}$ & $2.0(1.8-2.5)^{\$}$ & 0.026 \\
\hline
\end{tabular}

Md (IQR): median (interquartile range 25\%-75\%); MCl: mild cognitive impairment; AD: Alzheimer's disease; s: seconds; m/s: meter/second; \&,\#,+: same symbols mean difference between groups 
trunk (rotation) and a lower number of steps than the other three groups. In the turn-to-sit subtask, non-fallers with MCI exhibited a higher average velocity of the trunk (flexion/extension) and a lower number of steps than the other two groups with $\mathrm{AD}$, and non-fallers with $\mathrm{AD}$ showed a lower average velocity of the trunk (rotation) than the other three groups (Table 3). In accordance with the results described, no significant difference was found in performances on the TUG and its subtasks between faller and non-faller older adults (with cognitive condition as the confounding variable).

\section{DISCUSSION}

Our aim was to compare performances on the TUG and its subtasks in the presence of $\mathrm{MCI} /$ mild $\mathrm{AD}$ and the occurrence of falls. In accordance with specific subtasks, total performance on the TUG distinguished fallers from non-fallers with $\mathrm{AD}$, fallers from non-fallers with MCI and non-fallers with MCI from non-fallers with $\mathrm{AD}$. Although no other difference was found in the total performance on the TUG, non-fallers with MCI and fallers with $\mathrm{AD}$ had different performances on the walking forward, turn and turn-to-sit subtasks; and fallers with MCI and non-fallers with $\mathrm{AD}$ differed on the turn-to-sit subtask. No difference was found between fallers with $\mathrm{MCI}$ and fallers with $\mathrm{AD}$.

The high prevalence of fallers among people with MCI and mild $\mathrm{AD}$ is in accordance with previous studies ${ }^{7,16}$. Fall risk in older people with cognitive impairment seems to be more influenced by impaired balance, reduced functional mobility and depressive symptoms, while controlling for age, years of education and cognition ${ }^{16}$. In the sample, only nonfallers with MCI did not have risk of falls, using a cut-off TUG score of 12.47 seconds for Brazilian community-dwelling older people ${ }^{2}$. The understanding about the risk of falls in specific cognitive impairment groups is important for a better targeting in preventing falls.

Previous works did not find any difference in the total performance on the TUG between older people with MCI and mild $\mathrm{AD}^{4,17}$. On the other hand, a retrospective study found significant differences in the TUG between MCI and mild AD communitydwelling older people comprising fallers and non-fallers ${ }^{18}$, with a cut-off score of 11.39 seconds (sensibility: $65 \%$, specificity: $69 \%$ ). Maquet et al. ${ }^{19}$ verified a lower gait speed at usual pace in older people with mild $\mathrm{AD}$ compared to those with $\mathrm{MCI}$, but none of the participants had reports of a fall in the previous six months. In the present study, non-fallers with MCI and non-fallers with mild $\mathrm{AD}$ showed differences in performances on the TUG and all subtasks, however fallers with MCI and fallers with mild $\mathrm{AD}$ had similar performances on mobility. Thus, the risk of falls should be taken into account when assessing differences in mobility between these two conditions.

In agreement with our results, Allali et al. ${ }^{20}$ did not find an association between falls and gait speed at usual pace in older people with mild $\mathrm{AD}$. In the present study, the difference in time spent on the TUG between non-fallers and fallers with $\mathrm{AD}$ was probably due to the performance on the turn-to-sit subtask. The turn-to-sit subtask can be complex and challenging for fallers with mild $\mathrm{AD}$, as it involves transition and turning activities and requires a high level of executive function, attention, perception and orientation in space ${ }^{21}$.

Table 3. Other mobility parameters of the TUG and subtasks by group.

\begin{tabular}{|c|c|c|c|c|c|}
\hline Variable, Md (IQR) & $\begin{array}{l}\text { Non-fallers with } \mathrm{MCl} \\
\qquad(\mathrm{n}=18)\end{array}$ & $\begin{array}{l}\text { Fallers with } \mathrm{MCl} \\
\qquad(n=20)\end{array}$ & $\begin{array}{l}\text { Non-fallers with } \\
\text { mild } A D(n=18)\end{array}$ & $\begin{array}{l}\text { Fallers with mild AD } \\
\qquad(n=19)\end{array}$ & $p$-value \\
\hline \multicolumn{6}{|l|}{ TUG } \\
\hline Steps (number) & $17.0(14.2-18.0)$ & $18.0(16.0-21.0)$ & $20.5(15.5-24.0)$ & $17.5(15.0-22.2)$ & 0.185 \\
\hline \multicolumn{6}{|l|}{ Sit-to-stand } \\
\hline V of trunk, F/E (o/s) & $42.6(40.4-51.0)^{+}$ & $41.9(32.4-50.8)$ & $35.6(27.6-40.7)^{+}$ & $41.0(37.1-48.6)$ & 0.012 \\
\hline \multicolumn{6}{|l|}{ Walking forward } \\
\hline First step - time (s) & $0.6(0.5-0.6)$ & $0.6(0.6-0.7)$ & $0.7(0.6-0.7)$ & $0.7(0.6-0.7)$ & 0.142 \\
\hline First step - length (m) & $0.2(0.2-0.3)$ & $0.2(0.1-0.3)$ & $0.1(0.1-0.3)$ & $0.2(0.1-0.2)$ & 0.139 \\
\hline Steps (number) & $4.7(4.0-5.0)$ & $5.0(5.0-7.0)$ & $5.8(4.9-7.7)$ & $5.3(5.0-6.0)$ & 0.073 \\
\hline \multicolumn{6}{|l|}{ Turn } \\
\hline V of trunk, R (o/s) & $76.0(63.9-89.3)^{\#,+, \$}$ & $62.4(50.8-72.6)^{\#}$ & $56.1(44.6-65.0)^{+}$ & $58.8(54.2-70.0)^{\$}$ & 0.003 \\
\hline Steps (number) & $3.3(3.0-4.3)^{\#,+, \$}$ & $5.0(3.6-5.0)^{\#}$ & $5.0(3.6-5.0)^{+}$ & $5.0(4.3-5.0)^{\$}$ & 0.007 \\
\hline \multicolumn{6}{|l|}{ Walking back } \\
\hline First step - time (s) & $0.6(0.6-0.8)$ & $0.6(0.6-0.7)$ & $0.6(0.6-0.8)$ & $0.6(0.5-0.8)$ & 0.553 \\
\hline First step - length (m) & $0.3(0.2-0.4)$ & $0.2(0.2-0.3)$ & $0.2(0.2-0.3)$ & $0.3(0.2-0.4)$ & 0.254 \\
\hline Steps (number) & $4.0(3.0-4.9)$ & $5.0(4.0-6.0)$ & $5.0(3.9-6.0)$ & $4.3(3.6-5.3)$ & 0.146 \\
\hline \multicolumn{6}{|l|}{ Turn-to-sit } \\
\hline V of trunk, F/E (o/s) & $38.3(30.1-45.8)^{+, \$}$ & $31.6(25.1-37.5)$ & $26.3(19.2-35.1)^{+}$ & $30.1(23.6-37.0)^{\$}$ & 0.013 \\
\hline V of trunk, R (o/s) & $41.1(34.6-49.2)^{+}$ & $40.7(35.5-43.8)^{\#}$ & $29.3(26.6-36.6)^{+, \$, \#}$ & $38.9(33.1-44.8)^{\$}$ & 0.014 \\
\hline Steps (number) & $3.8(3.0-4.0)^{+, \$}$ & $4.0(3.7-4.7)$ & $4.5(4.0-5.8)^{+}$ & $4.0(4.0-4.8)^{\$}$ & 0.016 \\
\hline
\end{tabular}


Among older people with MCI, fallers and non-fallers had different performances on the TUG walking forward and turn subtasks. The results of the walking forward subtask are in accordance with previous studies, which found an association between falls and slow gait speed at usual pace in older people with $\mathrm{MCI}^{20,22}$. Altered performance on the turn subtask is associated with poor executive function in older people with $\mathrm{MCI}^{12}$. In addition, executive function is strongly associated with risk of falls among older adults ${ }^{23}$, which could justify the worse performance on the turn subtask in fallers with MCI. Other points could have influenced these results, such as different MCI subtypes, functional status and depressive symptoms ${ }^{24}$.

Non-fallers with mild $\mathrm{AD}$ had the worst performance on the turn-to-sit subtask and, in general, they took more time to perform the TUG compared to other volunteers. Fallers with mild to moderate $\mathrm{AD}$ seem to have more cerebral lesions and alterations in cognition than non-fallers ${ }^{25}$. Therefore, besides differences in performance on the TUG according to cognitive status, non-fallers with mild $\mathrm{AD}$ may have better perception of their own abilities and awareness of their alterations than fallers with mild $\mathrm{AD}$, which could be associated with the longer time taken on the mobility performance.

The assessment of the TUG subtasks is especially important when analyzing both fall and cognitive status. In this work, non-fallers with $\mathrm{MCI}$ and fallers with $\mathrm{AD}$, as well as fallers with $\mathrm{MCI}$ and non-fallers with $\mathrm{AD}$, had differences only in specific subtasks and not in total performance on the TUG. Mancini et al. ${ }^{26}$ found that the quality of turning mobility during daily life is associated with fall status and specific cognitive domains, including visuospatial and memory functions. More studies taking into account both fall and cognitive status are needed to better understand mobility impairment in older people.

The present study had some limitations, including the small convenience sample, physical limitation of the capture field and the non-application of the Minnesota Leisure Time
Activities Questionnaire after the follow-up. Although all participants were able to walk at least 10 meters without a walking aid, rheumatologic/orthopedic conditions and absence of physical therapy treatment were not included as selection criteria because of difficulty of recruiting older people with $\mathrm{MCI}$ and mild $\mathrm{AD}$ in Brazil. Nevertheless, we used standardized procedures regarding the TUG (such as the length of the walkway and the dimensions of the chair) and reliable and reproducible tools to assess mobility, and we conducted a prospective analysis of falls. The present study gives new information on the associations between mobility impairment, falls and the presence of $\mathrm{MCI} /$ mild $\mathrm{AD}$, which can be useful for developing effective strategies to screen and prevent mobility impairment and risk of falls in older people with cognitive impairment. The gait speed/time spent on the TUG and its subtasks distinguished older people's profiles according to fall and cognitive status, which are easier variables to collect than other mobility parameters analyzed in this study. New studies that combine diagnostic status and temporal parameters of each TUG subtask are needed to better predict the occurrence of falls in clinical practice.

In accordance with specific subtasks, total performance on the TUG distinguished fallers from non-fallers with $\mathrm{AD}$, fallers from non-fallers with $\mathrm{MCI}$ and non-fallers with $\mathrm{MCI}$ from non-fallers with AD. Although no other difference was found in total performance on the TUG, non-fallers with MCI and fallers with $\mathrm{AD}$ showed different performances on the walking forward, turn and turn-to-sit subtasks; and fallers with $\mathrm{MCI}$ and non-fallers with $\mathrm{AD}$ differed on the turn-to-sit subtask. Fallers with MCI and fallers with $\mathrm{AD}$ had similar performances on the TUG and subtasks. The assessment of fall status is helpful for better understanding of mobility impairment in older people with $\mathrm{MCI} / \mathrm{mild} \mathrm{AD}$. The analysis of the TUG subtasks is important in the differentiation of profiles according to both fall and cognitive status.

\section{References}

1. Bergland A. Jørgensen L, Emaus N, Strand BH. Mobility as a predictor of all-cause mortality in older men and women: 11.8 year follow-up in the Troms $\varnothing$ study. BMC Health Serv Res. 2017;17(1):22. https://doi.org/10.1186/s12913-016-1950-0

2. Alexandre TS, Meira DM, Rico NC, Mizuta SK. Accuracy of Timed Up and Go Test for screening risk of falls among communitydwelling elderly. Rev Bras Fisioter. 2012 Sep-Oct;16(5):381-8. https://doi.org/10.1590/S1413-35552012005000041

3. Mirelman A, Weiss A, Buchman AS, Bennett DA, Giladi N, Hausdorff JM. Association between performance on Timed Up and Go subtasks and mild cognitive impairment: further insights into the links between cognitive and motor function. J Am Geriatr Soc. 2014 Apr;62(4):673-8. https://doi.org/10.1111/jgs.12734

4. Ansai JH, Andrade LP, Rossi PG, Takahashi AC, Vale FA, Rebelatto JR. Gait, dual task and history of falls in elderly with preserved cognition, mild cognitive impairment, and mild Alzheimer's disease. Braz J Phys Ther. 2017 Mar - Apr;21(2):144-51. https://doi.org/10.1016/j.bjpt.2017.03.010
5. Gillain S, Warzee E, Lekeu F, Wojtasik V, Maquet D, Croisier JL et al. The value of instrumental gait analysis in elderly healthy, $\mathrm{MCl}$ or Alzheimer's disease subjects and a comparison with other clinical tests used in single and dual-task conditions. Ann Phys Rehabil Med. 2009 Jul;52(6):453-74. https://doi.org/10.1016/j.rehab.2008.10.004

6. Taylor ME, Delbaere K, Mikolaizak AS, Lord SR, Close JC. Gait parameter risk factors for falls under simple and dual task conditions in cognitively impaired older people. Gait Posture. 2013 Jan;37(1):126-30. https://doi.org/10.1016/j.gaitpost.2012.06.024

7. Allan LM, Ballard CG, Rowan EN, Kenny RA. Incidence and prediction of falls in dementia: a prospective study in older people. PLoS One. 2009;4(5):e5521. https://doi.org/10.1371/journal.pone.0005521

8. Zakaria NA, Kuwae Y, Tamura T, Minato K, Kanaya S. Quantitative analysis of fall risk using TUG test. Comput Methods Biomech Biomed Engin. 2015;18(4):426-37. https://doi.org/10.1080/10255842.2013.805211

9. Montaño MB, Ramos LR. Validity of the Portuguese version of Clinical Dementia Rating. Rev Saúde Pública 2005;39(6):1-5. https://doi.org/10.1590/S0034-89102005000600007 
10. American Psychiatric Association. Diagnostic and Statistical manual of mental disorders. 4th ed. Washington: American Psychiatric Association; 2000.

11. Lustosa LP, Pereira DS, Dias RC, Britto RR, Parentoni NA, Pereira LS. Translation and cultural adaptation of the Minnesota Leisure Time Activities Questionnaire in community-dwelling older people. Geriatr Gerontol. 2011;5(2):57-65.

12. Ansai JH, Andrade LP, Nakagawa TH, Vale FA, Caetano MJ, Lord SR et al. Cognitive correlates of Timed up and go subtasks in older people with preserved cognition, mild cognitive impairment and Alzheimer's disease. Am J Phys Med Rehabil. 2017 Oct;96(10):700-5. https://doi.org/10.1097/PHM.0000000000000722

13. Higashi Y, Yamakoshi K, Fujimoto T, Sekine M, Tamura T. Quantitative evaluation of movement using the timed upand-go test. IEEE Eng Med Biol Mag. 2008;27(4):38-46. https://doi.org/10.1109/MEMB.2008.919494

14. Galán-Mercant A, Cuesta-Vargas Al. Differences in trunk accelerometry between frail and non-frail elderly persons in functional tasks. BMC Res Notes. 2014 Feb;7(1):100. https://doi.org/10.1186/1756-0500-7-100

15. The prevention of falls in later life. A report of the Kellogg International Work Group on the Prevention of Falls by the Elderly. Dan Med Bull. 1987 Apr;34(4 Suppl 4):1-24.P

16. Taylor ME, Delbaere K, Lord SR, Mikolaizak AS, Brodaty H, Close JC. Neuropsychological, physical, and functional mobility measures associated with falls in cognitively impaired older adults. J Gerontol A Biol Sci Med Sci. 2014 Aug;69(8):987-95. https://doi.org/10.1093/gerona/glt166

17. Pettersson AF, Olsson E, Wahlund LO. Effect of divided attention on gait in subjects with and without cognitive impairment. J Geriatr Psychiatry Neurol. 2007 Mar;20(1):58-62. https://doi.org/10.1177/0891988706293528

18. Borges SM, Radanovic M, Forlenza OV. Functional mobility in a divided attention task in older adults with cognitive impairment. J Mot Behav. 2015;47(5):378-85. https://doi.org/10.1080/00222895.2014.998331
19. Maquet D, Lekeu F, Warzee E, Gillain S, Wojtasik V, Salmon E et al. Gait analysis in elderly adult patients with mild cognitive impairment and patients with mild Alzheimer's disease: simple versus dual task: a preliminary report. Clin Physiol Funct Imaging. 2010 Jan;30(1):51-6. https://doi.org/10.1111/j.1475-097X.2009.00903.x

20. Allali G, Launay CP, Blumen HM, Callisaya ML, De Cock AM, Kressig RW et al.; Biomathics Consortium. Falls, Cognitive Impairment, and Gait Performance: Results From the GOOD Initiative. J Am Med Dir Assoc. 2017 Apr;18(4):335-40. https://doi.org/10.1016/j.jamda.2016.10.008

21. Donoghue OA, Horgan NF, Savva GM, Cronin H, O'Regan C, Kenny RA. Association between timed up-and-go and memory, executive function, and processing speed.J Am Geriatr Soc. 2012 Sep;60(9):1681-6. https://doi.org/10.1111/j.1532-5415.2012.04120.x

22. Doi T, Shimada H, Makizako H, Tsutsumimoto K, Uemura K, Anan Y et al. Cognitive function and gait speed under normal and dual-task walking among older adults with mild cognitive impairment. BMC Neurol. 2014 Apr;14(1):67. https://doi.org/10.1186/1471-2377-14-67

23. Muir SW, Speechley M, Wells J, Borrie M, Gopaul K, MonteroOdasso M. Gait assessment in mild cognitive impairment and Alzheimer's disease: the effect of dual-task challenges across the cognitive spectrum. Gait Posture. 2012 Jan;35(1):96-100. https://doi.org/10.1016/j.gaitpost.2011.08.014

24. Ansai JH, Andrade LP, Masse FA, Gonçalves J, Takahashi ACM, Vale FA et al. Risk factors for falls in older adults with mild cognitive impairment and mild Alzheimer disease.J Geriatr Phys Ther. 2017 Mar 3. https://doi.org/10.1519/JPT.0000000000000135

25. Horikawa E, Matsui T, Arai H, Seki T, Iwasaki K, Sasaki H. Risk of falls in Alzheimer's disease: a prospective study. Intern Med. 2005 Jul;44(7):717-21. https://doi.org/10.2169/internalmedicine.44.717

26. Mancini M, Schlueter H, El-Gohary M, Mattek N, Duncan C, Kaye J et al. Continuous monitoring of turning mobility and its association to falls and cognitive function: a pilot study. J Gerontol A Biol Sci Med Sci. 2016 Aug;71(8):1102-8. https://doi.org/10.1093/gerona/glw019 